\title{
Histoire et critique textuelle des documents arabes et syriaques
}

\author{
Henri Hugonnard-Roche
}

\section{OpenEdition \\ Journals}

Édition électronique

URL : https://journals.openedition.org/ashp/363

DOI : 10.4000/ashp.363

ISSN : 1969-6310

Éditeur

Publications de l'École Pratique des Hautes Études

Édition imprimée

Date de publication : 1 octobre 2008

Pagination : 36-37

ISSN : 0766-0677

\section{Référence électronique}

Henri Hugonnard-Roche, "Histoire et critique textuelle des documents arabes et syriaques », Annuaire de l'École pratique des hautes études (EPHE), Section des sciences historiques et philologiques [En ligne],

139 | 2008, mis en ligne le 19 novembre 2008, consulté le 12 juillet 2021. URL : http:// journals.openedition.org/ashp/363; DOI : https://doi.org/10.4000/ashp.363 


\title{
HISTOIRE ET CRITIQUE TEXTUELLE DES DOCUMENTS ARABES ET SYRIAQUES
}

\author{
Directeur d'études : M. Henri Hugonnard-Roche
}

Programme de l'année 2006-2007 : I. Sergius de Resh 'ayna sur les Catégories d'Aristote (syriaque). - II. Logique et théorie de la science (arabe).

\section{Sergius de Resh 'ayna sur les Catégories d'Aristote (syriaque)}

Ainsi que nous l'avons déjà dit, la lecture du commentaire composé par Sergius de Resh'ayna sur les Catégories d'Aristote est une entreprise de longue haleine, étant donné que les conférences de syriaque n'ont lieu qu'une semaine sur deux. Durant cette année, donc, nous avons repris une fois encore cette lecture, avec les mêmes préoccupations que les années précédentes, c'est-à-dire en expliquant le texte de Sergius et en le comparant, autant que possible, avec les commentaires alexandrins dont il est très proche, ceux d'Ammonius et de Philopon tout particulièrement. Nous avons repris la lecture du livre III, dont le sujet principal est la substance, au passage où nous étions arrivés l'année précédente, c'est-à-dire à la distinction entre la substance première et la substance seconde. Rappelons, comme précédemment, que le texte de Sergius est inédit et que nous le lisons dans les trois manuscrits de Paris (BNF, syr. 354), de Londres (British Library, Add. 14658) et de Birmingham (Mingana 606).

Après divers préliminaires que nous avons mentionnés dans nos précédents rapports, Sergius entame l'examen de la substance par la question de la division entre substance première et substance seconde. Ceci implique cependant l'étude d'un nouveau préliminaire, à savoir de quelles manières peut se comprendre une division. Sergius passe ainsi en revue la division d'un tout en ses parties, d'un genre en ses espèces, et celle d'une expression homonyme en ses référents, pour conclure que la substance ne se divise d'aucune de ces manières. La division de la substance est une division selon le rang. La question qui vient alors est celle de savoir pourquoi Aristote pose comme première la substance singulière, contrairement à l'habitude qu'ont les philosophes de priser les choses générales. La raison en est que, tout comme la substance singulière est première pour les accidents qui ont en elle leur subsistance, elle est première relativement à la substance générique, en ce que celle-ci n'existe qu'en tant qu'elle est dite de la substance singulière. Sergius expose ensuite pourquoi les accidents ne peuvent être appelés des substances troisièmes : ils ne signifient jamais un individu quel qu'il soit, et ils ne peuvent être le substrat d'une prédication substantielle. Ces remarques posées, Sergius aborde enfin la question de la définition de la substance. La substance, étant un genre suprême, ne peut se définir selon la règle de toute définition, qui requiert que l'on dise le genre et la différence spécifique. À la définition, Aristote substitue la caractérisation par le propre. En conséquence, Sergius 
est conduit, par son constant souci pédagogique, à examiner ce qu'est le propre et de combien de manières il se dit. Il reprend, pour ce faire, la quadripartition du propre par Porphyre, à travers l'exposé qu'en fait Ammonius dans son commentaire sur l'Isagogè. C'est seulement après cette explicitation de la notion de propre que Sergius passera à la description des divers propres utilisés par Aristote pour caractériser la substance. Tel est le point où notre lecture du traité de Sergius nous a mené au cours de l'année. Nous avons pu mesurer, encore une fois, au cours de notre lecture, combien Sergius est proche de la tradition du commentarisme grec représentée par les textes d'Ammonius et de Philopon.

\section{Logique et théorie de la science (arabe)}

Dans la seconde conférence, consacrée aux textes arabes, nous avons poursuivi notre enquête sur les œuvres arabes de logique se rapportant à la « logique hypothétique », c'est-à-dire celle des arguments contenant une prémisse de type conditionnel (si ..., alors ...) ou disjonctif (ou bien ... ou bien ...). Après la lecture d'une partie de l'Abrégé de logique, composé par Averroès (1126-1198), qui nous avait occupé l'année précédente, nous avons entrepris, au cours de la présente année, l'étude d'un autre texte d'Averroès. Il s'agit de l'une des Questions que le philosophe a consacrées à divers sujets de logique. Cette question porte précisément sur le syllogisme hypothétique et elle est consacrée pour une large part à la critique des opinions de Fārābī et surtout d'Avicenne sur ce sujet. Nous avons commencé la lecture et l'explication de ce texte, dans l'édition procurée par Ğamal al-Dīn al-'Alawī : Abū al-Walīd Ibn Rušd, Maqālāt fì al-manțiq wa-l- 'ilm al-țabī' '̆, Casablanca, 1983, p. 187-207. Nous avons consulté aussi le manuscrit unique dans lequel ce texte est conservé, Escorial, 632, fol. 125r-135r. Nous avons également utilisé la version latine composée à partir de la version hébraïque de Samuel ben Jehuda ben Meshullam (en 1320) par le grand traducteur Abraham de Balmes (mort en 1523), que nous lisions dans la grande édition des commentaires d'Averroès par les Giunta, Venise 1562-1574 (réimpr. Minerva, Francfort, 1962, tome I 2b, fol. 92-98, sous le titre De conditionali, an per ipsum ostendatur quoesitum primum ignotum). 